\title{
HUBUNGAN KINERJA PERAWAT DENGAN KEPUASAN PASIEN (Studi di Puskesmas Kumpai Batu Atas Kabupaten Kotawaringin Barat Kalimantan Tengah)
}

\author{
Anis Novitasari ${ }^{1}$ Christina T Setiawan $^{2}$ Rahaju Wiludjeng $^{3}$ \\ ${ }^{1}$ STIKes Insan Cendekia Medika Jombang ${ }^{23}$ STIKes Borneo Cendekia Medika \\ Pangkalan Bun \\ ${ }^{1}$ email : anisnovitasari@gmail.com, ${ }^{2}$ email : csetiawan.366@gmail.com, ${ }^{3}$ email : \\ ira.wiludjeng@gmail.com
}

\begin{abstract}
ABSTRAK
Pendahuluan: Masalah kesehatan masyarakat semakin berkembangnya, maka tuntutan untuk mendapatkan pelayanan kesehatan yang lebih bermutu juga meningkat. Begitu banyak masalah pelayanan kesehatan dalam melakukan pengobatan atau perawatan. Rasa keinginan kepuasan dalam pemberiaan pelayanan kesehatan merupakan masalah utama dalam ruang lingkup tatanan pelayanan keperawatan yang diberikan pada pasien. Penelitian ini bertujuan memerikan analisa kinerja perawat dengan kepuasan pasien di Puskesmas Kumpai Batu Atas Kabupaten Kotawaringin Barat. Metode: Penelitian ini memiliki bentuk penelitian kuantitatif dengan pendekatan cross sectional. Populasi dalam penelitian ini 486 orang dengan teknik pengambilan simple random sampling dan didapatkan 83 orang. Dimana terdapat 2 variabel yaitu independen (kinerja perawat) dan variabel dependen (kepuasan pasien) dengan instrumen lembar kuesioner. Hasil penelitian: menunjukkan kinerja perawat di Puskesmas Kumpai Batu Atas sejumlah 42 orang $(50,6 \%)$ termasuk kategori sedang, kepuasan pasien sejumlah $50(60,2 \%)$ termasuk kategori sedang. Ada hubungan kinerja perawat dengan kepuasan pasien di Puskesmas Kumpai Batu Atas Kabupaten Kotawaringin Barat ( $p$ value 0,011). Kesimpulan: penelitian ini adalah H0 ditolak, H1 diterima artinya ada hubungan kinerja perawat dengan kepuasan pasien di Puskesmas Kumpai Batu Atas Kabupaten Kotawaringin Barat.
\end{abstract}

Kata kunci : Kepuasan pasien, Kinerja perawat,Puskesmas

\section{RELATIONSHIP WITH THE NURSE PERFORMANCE SATISFACTION (Study at Puskesmas Kumpai Batu Atas District of Kotawaringin Barat Central Kalimantan)}

\begin{abstract}
Introduction : Public health problems are growing, so the demand for better quality health services also increases. So many problems that patients experience when they first come to health care in the treatment or treatment. The sense of desire for satisfaction in the delivery of health services is a major problem in the scope of the nursing service order given to the patient. This study aims to describe the performance of nurses with patient satisfaction in Puskesmas Kumpai Batu Atas
\end{abstract}


Kotawaringin Barat District. Method: This research has a form of quantitative research with cross sectional approach. The population in this study is 486 people with simple random sampling technique and got 83 people. Where there are 2 variables that are independent (nurse performance) and dependent variable (patient satisfaction) with instrument of questionnaire sheet. Result: of the research shows that the performance of nurses at Puskesmas Kumpai Batu Atas is 42 people (50,6\%) including medium category, patient satisfaction 50 (60,2\%) including medium category. There is relationship of nurse performance with patient satisfaction at Puskesmas Kumpai Batu Atas Regency Kotawaringin Barat (p value 0,011). Conclusion: of this research is $\mathrm{HO}$ rejected, $\mathrm{HI}$ accepted means there is relation of nurse performance with patient satisfaction at Puskesmas Kumpai Batu Atas Regency Kotawaringin Barat.

Keywords: Patient satisfaction, Nurse performance,Puskesmas

\section{PENDAHULUAN}

Masalah kesehatan masyarakat
semakin berkembangnya, maka
tuntutan untuk mendapatkan
pelayanan kesehatan yang lebih
bermutu juga meningkat. Begitu
banyak masalah yang dialami pasien
ketika pertama kali datang ke
pelayanan kesehatan dalam melakukan
pengobatan atau perawatan. Rasa
keinginan kepuasan dalam pemberiaan
pelayanan kesehatan merupakan
masalah utama dalam ruang lingkup
tatanan pelayanan keperawatan yang
diberikan pada pasien.

Menurut (Dinkes, 2014, 41), di Provinsi Kalimantan Tengah pada tahun 2014 tenaga perawat berjumlah 3963, sedangkan di tahun 2015 berjumlah 3885 tenaga perawat, di tahun 2015 tenaga perawat sedikit rendah dari tahun sebelumnya. Berdasarkan Studi pendahuluan di Puskesmas Kumpai Batu atas pada tanggal 26 Maret 2018, peneliti mendapatkan 10 pasien, $6(60 \%)$ pasien menyatakan kurang puas dengan kinerja perawat. Sebanyak 4 (40\%) pasien menyatakan puas.
Kejadian pelayanan yang kurang memuaskan pasien disebabkan oleh salah satunya tingkat pelayanan keperawatan yang kurung bisa manjadikan respon pasien nyaman. Sikap perawat dalam memberikan pelayanan yang kurang memuaskan nantinya memiliki dampak berupa tingkat kepuasan yang tidak bagus (Nursalam, 2013, 57).

Upaya dalam memberikan kepuasan pasien dalam mendapatkan pelayanan yang diperoleh dari kinerja perawat, maka peneliti sangat tertarik dengan masalah tersebut dan penulis ingin melakukan penelitian tentang "Hubungan kinerja perawat dengan kepuasan pasien dipuskesmas kumpai batu atas kabupaten kotawaringin barat".

\section{METODE PENELITIAN}

Penelitian yang sudah dilakukan berjenis analitik korelasi, dimana penelimi mencari hubungan setiap variabel denga cara menganalisisnya. Pendekatan berupa cross sectional, dengn cara pengambilan data dilakukan 
dalam wakru sekali (Notoatmodjo, 2010, 87).

Populasi merupakan keseluruhan data atas objek atau subjek penelitian, dimana populasi dalam penelitian ini adalah seluruh pasien yang pernah datang ke Puskesmas Kumpai Batu Atas pada bulan April 2018 sejumlah 486 pasien (Sugiyono, 2012, 68) .

Teknik sampling penelitian menggunakan simple random sampling yaitu pengambilan data penelitian yang dilakukan secar acak (Arikunto, 2006, 58). sampel penelitian adalah Sebagian pasien yang datang dan pernah ke Puskesmas Kumpai Batu Atas dengan jumlah 83 pasien. Instrumen yang peneliti gunakan berupa lembar kuesioner.

\section{HASIL PENELITIAN}

\section{Data Umum}

Tabel 1 Frekuensi responden berdasarkan umur pasien di Puskesmas Kumpai Batu Atas Kabupaten Kotawaringin Barat

\begin{tabular}{ccc}
\hline Umur & Jumlah & $\begin{array}{c}\text { Persentase } \\
(\mathbf{\%})\end{array}$ \\
\hline $12-16$ & 7 & 8,43 \\
\hline $17-25$ & 5 & 6,02 \\
\hline $26-35$ & 27 & 32,53 \\
\hline $36-45$ & 10 & 12,05 \\
\hline $45-55$ & 20 & 24,1 \\
\hline $56-65$ & 10 & 12,05 \\
\hline$>65$ & 4 & 4,82 \\
\hline Total & 83 & 100 \\
\hline Sumber: data primer, 2018 &
\end{tabular}

Tabel 1 hasilnya bahwa hampir setengah umur responden di Puskesmas Kumpai Batu Atas Adalah 26-35 sebanyak 27 responden $(32,53 \%)$.
Tabel 2 Distribusi frekuensi responden berdasarkan jenis kelamin responden di Puskesmas Kumpai Batu Atas Kabupaten Kotawaringin Barat

\begin{tabular}{lcc}
\hline $\begin{array}{c}\text { Jenis } \\
\text { kelamin }\end{array}$ & Jumlah & $\begin{array}{c}\text { Persentase } \\
(\boldsymbol{\%})\end{array}$ \\
\hline Laki-laki & 37 & 44,58 \\
Perempuan & 46 & 55,42 \\
\hline \multicolumn{1}{c}{ Total } & 83 & 100 \\
\hline Sumber: data primer, 2018 &
\end{tabular}

Tabel 2 hasilnya bahwa sebagian besar jenis kelamin responden di Puskesmas Kumpai Batu Atas Adalah berjenis kelamin perempuan sejumlah 46 orang atau 55,42\%.

Tabel 3 Distribusi frekuensi responden berdasarkan pendidikan terakhir pasien di Puskesmas Kumpai Batu Atas Kabupaten Kotawaringin Barat

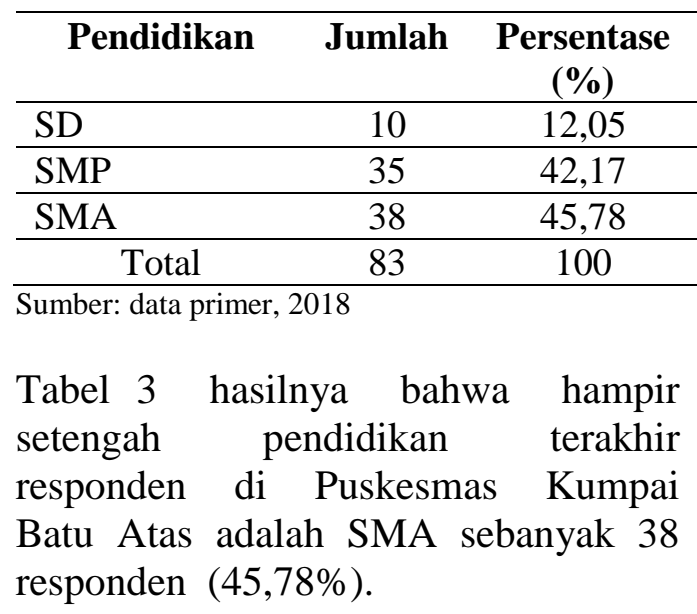

Tabel 4 Distribusi frekuensi responden berdasarkan pekerjaan responden di Puskesmas Kumpai Batu Atas Kabupaten Kotawaringin Barat

\begin{tabular}{lcc}
\hline Pekerjaan & Jumlah & $\begin{array}{c}\text { Persentase } \\
(\mathbf{\%})\end{array}$ \\
\hline Bekerja & 66 & 79,52 \\
\hline Tidak bekerja & 17 & 20,48 \\
\hline \multicolumn{1}{c}{ Total } & 83 & 100 \\
\hline Sumber: data primer, 2018 &
\end{tabular}


Tabel 4 hasilnya bahwa hampir seluruhnya pekerjaan responden di Puskesmas Kumpai Batu Atas adalah Bekerja sejumlah 66 orang atau $79,52 \%$.

\begin{tabular}{|c|c|c|c|c|c|}
\hline & \multicolumn{4}{|c|}{ Kepuasan } & \multirow{2}{*}{$\begin{array}{c}\text { Uji } \\
\text { Rank } \\
\text { Spear } \\
\text { man }\end{array}$} \\
\hline & $\begin{array}{l}\text { Tin } \\
\text { ggi }\end{array}$ & $\begin{array}{l}\text { sed } \\
\text { ang }\end{array}$ & $\begin{array}{l}\text { Rend } \\
\text { ah }\end{array}$ & $\begin{array}{l}\text { Tot } \\
\text { al }\end{array}$ & \\
\hline $\begin{array}{l}\text { Ki Baik } \\
\text { ne } \\
\text { rja }\end{array}$ & $\begin{array}{l}\text { Coun } \\
\mathrm{t} \quad 0\end{array}$ & 2 & 1 & 3 & \\
\hline \multirow{2}{*}{ rja } & $\%$ of & 2.4 & & 3.6 & \\
\hline & Total $0 \%$ & $\%$ & $1.2 \%$ & $\%$ & \\
\hline \multirow[t]{2}{*}{$\begin{array}{l}\text { Seda } \\
\text { ng }\end{array}$} & $\begin{array}{l}\text { Coun } \\
\mathrm{t}\end{array}$ & 30 & 11 & 42 & \\
\hline & $\%$ of 1.2 & $\begin{array}{l}36 . \\
1 \%\end{array}$ & 13.3 & 50. & 0,011 \\
\hline \multirow[t]{3}{*}{$\begin{array}{l}\text { Buru } \\
\mathrm{k}\end{array}$} & $\begin{array}{l}\text { Coun } 0 \\
\mathrm{t}\end{array}$ & 18 & 20 & 38 & \\
\hline & $\%$ of & 21. & 24.1 & 45. & \\
\hline & Total $.0 \%$ & $7 \%$ & $\%$ & $8 \%$ & \\
\hline \multirow[t]{3}{*}{ Total } & $\begin{array}{l}\text { Coun } \\
t\end{array}$ & 50 & 32 & 83 & \\
\hline & $\%$ of 1.2 & 60. & 38.6 & 100 & \\
\hline & Total \% & $2 \%$ & $\%$ & $.0 \%$ & \\
\hline
\end{tabular}

\section{Data Khusus}

Tabel 5 Distribusi frekuensi berdasarkan responden nilai kinerja perawat di Puskesmas Kumpai Batu Atas Kabupaten Kotawaringin Barat

\begin{tabular}{llc}
\hline $\begin{array}{c}\text { Kinerja } \\
\text { Perawat }\end{array}$ & Frekuensi & $\begin{array}{c}\text { Presentase } \\
(\boldsymbol{\%})\end{array}$ \\
\hline Baik & 3 & $3,6 \%$ \\
Sedang & 42 & $50,6 \%$ \\
Buruk & 38 & $45,8 \%$ \\
\hline Total & 83 & $100,0 \%$ \\
\hline
\end{tabular}

Sumber: data primer, 2018

Tabel 5 hasilnya bahwa setengah Kinerja perawat di Puskesmas Kumpai Batu Atas adalah bernilai sedang dengan 42 responden atau $51,8 \%$.

Tabel 6 Distribusi frekuensi berdasarkan responden nilai kepuasan pasien di Puskesmas Kumpai Batu Atas Kabupaten Kotawaringin Barat

\begin{tabular}{ccc}
\hline $\begin{array}{c}\text { Kepuasan } \\
\text { Pasien }\end{array}$ & Frekuensi & $\begin{array}{c}\text { Presentase } \\
(\mathbf{\%})\end{array}$ \\
\hline Tinggi & 1 & $1,2 \%$ \\
Sedang & 50 & $60,2 \%$ \\
Rendah & 32 & $38,6 \%$ \\
\hline \multicolumn{1}{c}{ Total } & 83 & $100,0 \%$ \\
\hline Sumber: data primer, 2018 &
\end{tabular}

Tabel 6 hasilnya bahwa sebagian besar kepuasan pasien di Puskesmas Kumpai Batu Atas Adalah bernilai sedang dengan 50 responden atau $60,2 \%$.

Tabel 7 Distribusi frekuensi responden berdasarkan hubungan kinerja perawat dengan kepuasan pasien di Puskesmas Kumpai Batu Atas Kabupaten Kotawaringin Barat

Berdasarkan uji analisa statistik parametrik dengan menggunakan uji rank spearman yang terdapat dalam komputer yaitu dengan tingkatkesalahan $\alpha=0,05$ nilai $\mathrm{p}=$ 0,011 yang berarti $p>0,05$. Penelitian yang telah dlakukan didapatkan hasil ada hubungan kinerja perawat dengan kepuasan pasien di Puskesmas Kumpai Batu Atas Kabupaten Kotawaringin Barat.

\section{PEMBAHASAN}

\section{Kinerja perawat di Puskesmas Kumpai Batu Atas Kabupaten Kotawaringin Barat}

Tabel 5 hasilnya bahwa setengah Kinerja perawat di Puskesmas Kumpai Batu Atas adalah bernilai 
sedang dengan 42 responden atau $51,8 \%$.

Peneliti mengemukankan pendapat bahwa dengan hasil yang diperoleh dari penelitian, dapat diperlihatkan bahwa kinerja perawat dalam tatanan pelayanan sudah memiliki kategore cukup yang dapat ditingkatkan menjadi lebih baik.

Menurut (Swarburg, 2000, 49) menerangkan pemberian pelaksaan terhadap layanan keperawatan yang dilaksanakan sesuai dengan kewenangan dan ugas yang sesuai prosedur pelaksanaannya. Kinerja perawat akan menjadi lebih baik jika perawat dapat meningkatkan kinerjanya.

\section{Kepuasan pasien di Puskesmas Kumpai Batu Atas Kabupaten Kotawaringin Barat}

Tabel 6 hasilnya bahwa sebagian besar kepuasan pasien di Puskesmas Kumpai Batu Atas adalah bernilai sedang dengan 50 responden atau $60,2 \%$.

Peneliti berpendapat bahwa tingkat kepuasan pelayanan keperawatan yang sesuai dengan penelitian yang telah dilakukan nilainya cukup, dimana memiliki arti bahwa kepuasan masih jauh dari yang di inginkan oleh penggunana pelayanan keperawatan.

(Nursalam, 2013, 38) yang mengatakan bahwa kepuasan pasien merupakan luapan perasaan yang bisa diunkapkan setelah mendapatkan pelayanan yang sesuia dengan apa yang telah diharapkan leh pasien berdasarkan lima karakteristik pelayanan keperawatan.

\section{Hubungan kinerja perawat dengan kepuasan pasien di Puskesmas Kumpai Batu Atas Kabupaten Kotawaringin Barat}

Dari tabel 7 untuk menganalisis hubungan kinerja perawat dengan kepuasan pasien di Puskesmas Kumpai Batu Atas di gunakan uji statistik yang tepat adalah spearman rank. Alasannya variabel independen (Kinerja perawat) adalah berskala ordinal sedangkan variabel dependen (kepuasan pasien) juga berskala ordinal, setelah dianalisis dengan bantuan spss for windows 16 diperoleh nilai $\mathrm{p}=0,011$.

Peneliti mengemukakan pendapat bahwa kinerja perawat memiliki pengaruh besar terhadap suatu tingkat kepuasan yang diberikan terhadapap pasien. Tingkat kepusan pasien inilah yang nantinya dijadikan tolak ukur tentang pelayanan kesehatan yang telah diberikan oleh perawat dan dapat dijadika salah sau wadah untuk meningkatkan kualutas pelayanan dalam memberikan kepuasan pasien.

(Mulyanto, 2012, 4), hasil penelitiannya memberikan hasil bahwa ada hubungan positif antara kinerja perawat dengan kepuasan pasien. penggambaran tentang penelitian tersebuat, dapat dijadikan suau ajuan bahwa cara mengimplementasi kinerja perawat dalam melaksanakan tugas, kewajiban, dan wewenang akan mempengaruhi tingkat kepuasaan pelayanan. Tidak hanya meningkatkan kredibilitas Rumah Sakit, tapi juga dapat meninggkatkan kredibilitas Puskesmas. 


\section{KESIMPULAN DAN SARAN}

\section{Kesimpulan}

1. Kinerja perawat di Puskesmas Kumpai Batu Atas sebagian besar adalah sedang dengan jumlah 42 responden atau 51,8\%.

2. Kepuasan Pasien di Puskesmas Kumpai Batu Atas adalah sebagian besar adalah sedang dengan jumlah50 responden atau $60,2 \%$.

3. Ada hubungan kinerja perawat dengan kepuasan pasien di Puskesmas Kumpai Batu Atas Kabupaten Kotawaringin Barat dengan nilai $\mathrm{p}=0,011$.

\section{Saran}

1. Dengan adanya kinerja perawat yang sedang, maka dari itu perawat harus terus meningkatkan kinerjanya dengan melakukan tindakan keperawatan mulai dari tindakan yang dilakukan perawat terhadap pasien seperti Kenyataan, Keandalan, Tanggung Jawab, Jaminan dan Empati.

2. Untuk kepuasan pasien yang sedang, kinerja perawat cukup dalam memberikan kepuasan terhadap pasien maka dari itu perawat harus terus memberikan kepuasan terhadap pasien dengan memberikan kinerja yang baik dan membuat pasien merasakan nyaman aman dan puas.

3. Puskesmas harus lebih memantau kinerja para perawat agar tingkat kepuasan pasien dalam tindakan yang diberikan meningkat, sehingga tidak ada keluhan baik dari pasien maupun keluarga pasien.
4. Untuk peneliti selanjutnya peneliti diharapkan dapat melakukan peneliian yang berkenaan dengan kinerja perawat dalam langkah memberikan tingkat kepuasan pasien. diaman variabel yang digunakan dapat berbeda dari yang pernah sudah ada.

\section{DAFTAR PUSTAKA}

Arikunto, S. 2006. Prosedur Penelitian Suatu Pendekatan Praktek. Pt Rhineka Cipta: Jakarta.

Dinas Kesehatan. 2014. Tenaga Kesehatan Provinsi Kalimantan Tengah.

http://www.depkes.go.id/resource s/download/profil/DINKES_KES _PROVINSI_2014/21_KALTENG 2015.pdf

Mulyanto, R. 2012. "hubungan positif antara kinerja perawat dengan kepuasan pasien Di Rumah Sakit Umum Derah Sultan Imanuddin Pangkalan Bun Kalimantan Tengah". Yogyakarta: Universitas Gadjah Mada.

Notoatmodjo. 2010. Metodologi penelitian kesehatan. Jakarta: Rineka Cipta.

Nursalam. 2013. Manajemen Keperawatan : Aplikasi dalam Praktik Keperawatan Profesional. Salemba Medika: Jakarta.

Sugiyono. 2012. Metode penelitian kuantitatif, kualitatif dan $R \& D$. Alfabeta: Bandung.

Swarburg R C (2000). Pengembangan Staf Keperawatan Serta Pengembangan SDM, Buku Kedokteran EGC, Jakarta 